\title{
Why Are There Still Monkeys?
}

\author{
William Eric Meikle $\cdot$ Eugenie C. Scott
}

Published online: 16 October 2010

(C) Springer Science+Business Media, LLC 2010

\begin{abstract}
The question "If humans evolved from monkeys, why are there still monkeys?" reveals a widespread and persistent misconception about the process and pattern of evolution. The concept of "cousins" is central to understanding and overcoming this particular obstacle to evolution education.
\end{abstract}

Keywords Human evolution · Fossils · Ancestors ·

Relatives · Concepts of evolution · Teaching human evolution

Popular misconceptions about evolution seem to have a life of their own. Some of the most common ones have persisted for decades, despite all efforts to correct them (Petto and Mead 2008; Mead and Scott 2010a; Mead and Scott 2010b). Some of these ideas seem to be firmly embedded in American culture - or sometimes to have even deeper roots in the Western historical tradition. They are passed on from generation to generation, typically outside of formal and informal educational institutions. These are not necessarily or distinctively creationist misconceptions. Rather, they are simply very common among students and the general public, regardless of what their beliefs may be about whether evolution has occurred. Educators need to be aware of and ready to counter such common misconceptions. Unless they are explicitly pointed out and debunked, they will persist, coexisting with standard concepts of evolution that may be learned in the classroom.

When talking to the general public or school groups about human evolution, we have found that if you discuss

W. E. Meikle $(\bowtie) \cdot$ E. C. Scott

National Center for Science Education,

P.O. Box 9477, Berkeley, CA 94709-0477, USA

e-mail: meikle@ncse.com evolution or answer questions about it long enough, one particular question will inevitably be asked. That question, of course, is "If humans evolved from monkeys, why are there still monkeys?" This is sometimes phrased in terms of "apes" instead of "monkeys," but the technical differences between these groups of primates are irrelevant to the significance of the question being asked and the unspoken assumptions that underlie it. Besides, it is not at all clear that most of the public can tell the difference between an ape and a monkey, as illustrated by the numerous portrayals of "monkeys" in the media by chimpanzees. One of us has described this question as "probably the second most common question I get on talk radio" (Scott 2009). ${ }^{1}$

When first encountering this question, it may not be clear how to respond. Why shouldn't there still be monkeys? What is the questioner thinking? After repeatedly confronting this question in various guises, we have recognized that it derives from a mistaken view of evolution shared by many people, including students. Its persistence among the general public suggests that many retain this view even after instruction in evolution.

The "why are there still monkeys" question reflects an interpretation of evolution as a series of progressive steps, from simple to complex. It sees modern organisms, whether living species or other groups, as representatives of the ancestral "stages" or "steps" of evolution, or even as the still-surviving ancestors themselves. This popular misconception often includes the unspoken assumption that the appearance of descendants must coincide with, if not result in, the disappearance of ancestors. One must change into the other, without any coexistence of the two. The unconscious model of evolution that appears to be the

\footnotetext{
${ }^{1}$ The most common question is, "Why is creationism such a problem in the United States and not elsewhere?"
} 
default mode for a great many people thus seems to be both linear and anagenetic.

What is missing from this view of evolution is the crucial role of branching or splitting in creating the tree of life (Mead 2009). Perhaps the easiest way to introduce a more accurate model of the relationships of contemporary species is through the analogy of human family categories, and especially that of "cousins." Students often don't recognize that they have two classes of relatives in their own families, lineal and collateral. The progressive, ladder model of evolution highlights only the lineal relatives: grandparents, parents, children, grandchildren, etc. However, collateral relatives such as cousins, aunts, nephews, and so forth are also family members. In any large extended family, it is likely that the majority of relatives will be collateral rather than lineal ones. So too in the extended family of all living things.

The notion that living species are cousins, and neither ancestors nor descendants of each other, is one of the most important understandings for students to acquire. This relationship results from the branching nature of evolution and reflects common ancestry. Those who ask why there are still monkeys implicitly conceive of the relationship of monkeys, apes, and humans as a lineal one where monkeys evolve into apes, and apes evolve into humans (Fig. 1a). This is incorrect on many levels, of course. First, it usually pictures living monkeys and apes as part of this linear trajectory, instead of ancient apes and monkeys. Second, ancient monkeys didn't evolve into apes. Monkeys from the New World are only distantly related to humans and apes, but even Old World monkeys didn't evolve into apes. Apes and Old World monkeys descended from a more generalized anthropoid common ancestor that lacked the derived traits of either monkeys or apes (McNulty 2010). Sometimes scientists refer to the common ancestors of modern apes and humans as "apes," though it would be clearer to students if we were more careful to distinguish such ancestors from living forms, perhaps by consistently referring to them as "fossil apes."
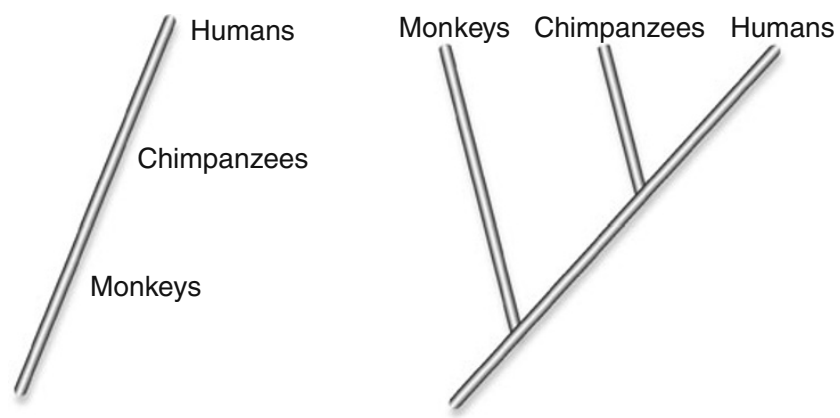

Fig. 1 Relationship of monkeys, an African ape, and humans. a Common misconception of monkeys being ancestral to apes and apes to humans. $\mathbf{b}$ The accurate relationship of these three groups
So, many students are wrong about the linear sequence monkeys - apes - humans. The historically accurate relationship is that apes are more closely related to humans than they are to monkeys, as shown in Fig. 1b. Humans and African apes share a more recent common ancestor than the two of them share with monkeys. The accurate relationship between an individual, a sibling, and a cousin is diagrammed in Fig. 2b. It is identical in form to the accurate relationship of a monkey, an ape, and a human. Would students visualize their relationship to their relatives as being that in Fig. 2a? Surely not! Yet this same error is regularly made about the relationship of monkeys, apes, and humans. Reminding students that living species are cousins rather than ancestors will help counter the misconception of evolution as linear rather than branching.

In fact, this "cousin" model of relationships is more than just a metaphor. Individuals are relatives, in a genetic sense, if they share genes derived from common ancestors. Related species also share genes, derived from their common ancestors. In each case, the percentage of genes shared reflects recency of common ancestry as well as the distance between any pair of relatives. We humans share more genes with modern apes than we do with monkeys; an individual will share more genes with a brother than with a cousin. For a detailed elaboration of the scientific approach to understanding the relationships of species to each other, see the Tree of Life Web Project (http://tolweb.org/tree/). For a more popular exposition of the meaning of cousins and family trees in an evolutionary context, see the Evolutionary Genealogy website (http://www.evogeneao. com/evo-gene.html).

So how should teachers and professors respond when confronted with the question, "if humans evolved from monkeys, why are there still monkeys?" Sometimes this and other questions about evolution are encountered in a fleeting context where there is not quite enough time to explain the full scope of evolutionary biology (Scott 2006)!

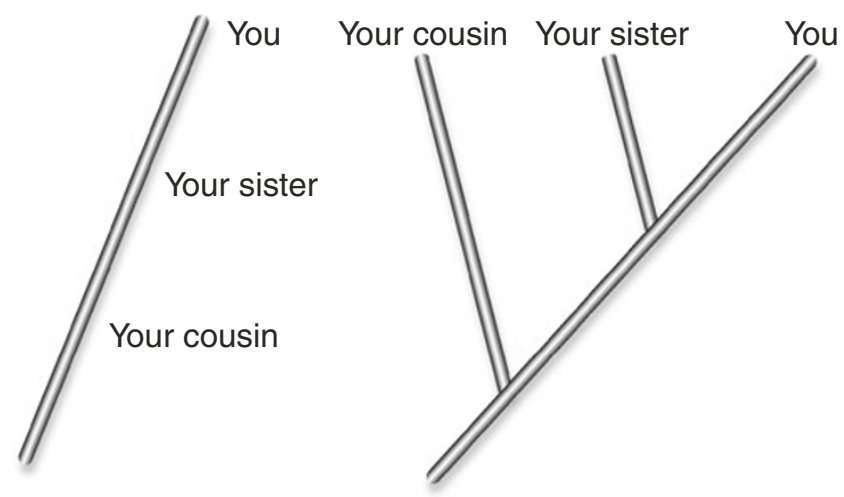

Fig. 2 Relationship within a family. a The relationship of relatives if the same reasoning were followed as in Fig. 1a. b The relationship among an individual, a sibling, and a cousin is accurately depicted 
The briefest possible response would be to emphasize that evolution deals with common ancestors. It is not that humans descended from apes and that apes descended from monkeys; rather, humans and apes share a common ancestor, and it is more recent than the common ancestor they both share with monkeys.

If you are in a classroom situation where you have a bit more time, use the analogy of a human family tree, as in Fig. 2a and b. It is no more correct that humans descended from apes and that apes descended from monkeys than that you descended from your siblings who in turn descended from your cousins. No one would ask, "If you evolved from your cousin, why is your cousin still here?" The question "if humans evolved from monkeys, why are there still monkeys?" is equally absurd to an evolutionary biologist. (We note with interest that the Young Earth Creationist organization Answers in Genesis (AiG) has very recently, September 21, 2010, posted among their "Arguments Christians Shouldn't Use" an article entitled "If Humans Evolved from Apes, Why Do Apes Exist Today?” (http:// www.answersingenesis.org/articles/2010/09/21/humansevolved-from-apes) We are pleased that $\mathrm{AiG}$ recognizes that this question "... shows a misunderstanding of what evolutionists actually believe about human evolution. The evolutionary concept of the origin of humans is not based on humans descending from modern apes but, rather, argues that humans and modern apes share a common ancestor." (Emphasis in original) Of course, AiG still completely rejects this scientific conclusion, but at least they understand it.)

Where it is possible to use diagrams or other illustrations, you can reinforce the point by noting that genetic information supports the genealogical relationships of the primates as more or less distant cousins: apes and humans are genetically closer to one another than they are to monkeys, just as an individual shares more genes with a sibling than with a cousin.

As with all misconceptions, this one will not be laid to rest without making students grapple with the conflict between their misconceptions and the scientific data. And of course, misconceptions remain resistant to change without the repeated reinforcement of accurate science. In this context, it is critical that teachers present evolution not as a linear sequence but as a branching and splitting pattern of lineages, with the end products being cousins.

Acknowledgments We thank Louise S. Mead and Glenn Branch for helpful discussion and suggestions and Steven Newton for preparing the figures.

\section{References}

McNulty KP. Apes and tricksters: the evolution and diversification of humans' closest relatives. Evol Edu Outreach. 2010;3:322-32.

Mead LS. Transforming our thinking about transitional forms. Evol Edu Outreach. 2009;2:310-14.

Mead LS, Scott EC. Problem concepts in evolution part I: purpose and design. Evol Edu Outreach. 2010a;3:78-81.

Mead LS, Scott EC. Problem concepts in evolution part II: cause and chance. Evol Edu Outreach. 2010b;3:261-4.

Petto AJ, Mead LS. Misconceptions about the evolution of complexity. Evol Edu Outreach. 2008;1:505-8.

Scott EC. Countering creationism with drive-by science. Gen Anthro. 2006; $13(2): 1-5$

Scott EC. Accept it: talk about evolution needs to evolve. Sci News. 2009;176(3):32. 